\title{
EXCLUSÃO E EDUCAÇÃO SOCIAL: CONCEITOS EM SUPERFÍCIE E FUNDO
}

\author{
Marlene Ribeiro*
}

RESUMO: O artigo trata da relação entre exclusão e educação social. Objetiva trazer elementos que permitam uma discussão sobre a realidade e as concepções de exclusão/inclusão e educação social, com o fim de re-velar ideologias e interesses que as informam. Trabalha com a hipótese de que existe uma disputa entre projetos sociais e educacionais contraditórios, resultando, daí, estratégias de combate à exclusão e promotoras de inclusão, encarnadas em concepções e práticas de educação social, como resposta às demandas de políticas sociais públicas provenientes das populações de crianças e jovens em situação de vulnerabilidade. A problematização desses conceitos - exclusão e educação social - poderá contribuir à formulação de políticas para a educação pública.

Palavras-chave: Exclusão. Educação social. Movimentos sociais. Trabalho e educação.

\section{EXCLUSION AND SOCIAL EDUCATION: SUPERFICIAL AND THOROUGH CONCEPTS}

ABSTRACT: This paper approaches the relationship between exclusion and social education. It aims at bringing out elements that lead to discuss reality and conceptions of social exclusion/inclusion and social education to dis-close the ideologies and interests that inform them. It develops the hypothesis that some kind of dispute between contradictory social and educational projects have resulted in strategies to fight exclusion and promote inclusion that are based on social education practices, as a response to the public social policies

* Doutora em Educação pela Universidade Federal do Rio Grande do Sul (UFRGS), coordenadora do GT "Trabalho e Educação" da ANPED e pesquisadora com o apoio da FAPERGS e do CNPq. E-mail: maribe@adufrgs.ufrgs.br 
Exclusão e educação social: conceitos em superfície e fundo

claimed by children and young people at risk. Problemizing these concepts - exclusion and social education - may bring some contributions to the formulation of public education policies.

Key words: Exclusion. Social education. Social movements. Work and education.

\section{Introdução}

$\mathscr{P}$

ós-modernidade e globalização - ideologias ${ }^{1}$ presas ao paradigma da acumulação flexível ${ }^{2}$ - fazem-nos crer na impossibilidade de ir ao fundo do real; a rapidez com que ocorrem as transformaçôes nos processos de produção de bens materiais e de conhecimento e a enorme mobilidade que assume a comunicação material e virtual só nos permitem contemplar a superfície do fenômeno. $\mathrm{O}$ real e o virtual confundem-se de modo que, mesmo que lhes fizéssemos um corte, qual seria o sentido de ver o fundo quando tudo permanece o mesmo, o capitalismo apregoado como o único caminho possível para o "desenvolvimento"?

$\mathrm{Na}$ contracorrente deste discurso hegemônico, que invade, inclusive, o pensamento acadêmico, afirmo a necessidade de que a vida tenha sentido, de que esse sentido conjugue a humanização, afirmada por Freire (1981a), com a emancipação, pensada por Marx (1993). Sem isso, o humano descamba para um processo de autodestruição, de perda de referências e de desumanização, como vem ocorrendo.

Trazendo para a nossa área, a educação, e na perspectiva de buscar sentido, de tentar atravessar a aparência do real, ou o fenômeno, para adentrar na sua essência (Kosik, 1976; Cury, 1989), é que dirijo minhas indagações à relação que se estabelece entre exclusão e educação social. Pretendo trazer alguns elementos que permitam uma discussão, ainda inicial, sobre a realidade e as concepções de exclusão/inclusão e educação social, com o fim de re-velar ideologias e interesses que as informam. Formulo a hipótese de que existe uma disputa entre projetos sociais e educacionais contraditórios, resultando, daí, estratégias de combate à exclusão e promotoras de inclusão, encarnadas em concepções e práticas de educação social, como resposta às demandas de políticas sociais públicas provenientes das populaçóes de crianças e jovens em situação de vulnerabilidade. 
Num primeiro momento e seguindo o curso dos que contemplam o mesmo/outro na animação contínua da superfície, ${ }^{3}$ poderíamos dizer que a educação social vem ao encontro da resolução de questôes decorrentes da exclusão social. Mas o que é exclusão social? Por que este conceito é tão difundido e se presta aos mais diversos usos e abusos? E a educação social, um conceito que emerge a partir dos anos de 1990, no auge da força das políticas neoliberais, o que seria? A educação é reconhecida, por parte das correntes teórico-epistemológicas - da mais conservadora à de esquerda mais radical -, pelo seu caráter social. Não é estranho que esse caráter social que a sustenta se torne apenas um adjetivo qualificativo? O que seria a educação sem este adjetivo? O que separa a educação simplesmente da educação qualificada como social, e o que une aquela a esta?

Julgo que a importância de problematizar esses conceitos - exclusão e educação social -, usados por pesquisadores preocupados com a educação brasileira, e que, por essa razão, propõem políticas para a educação pública, esteja em des-velar os interesses de classe incorporados na tradução dos sentidos de exclusão e educação social. Com isso, não estou afirmando que existam conceitos verdadeiros e que estes - o de exclusão e o de educação social - sejam falsos. Valho-me da noção de ideologia, porém atentando para análises sobre "verdade e poder", feitas por Foucault, o qual recomenda que esta noção "não deve ser utilizada sem precauções" (1984, p. 7). Penso que o conhecimento legítimo é o que conseguiu impor-se por relações de poder, suprimindo ou subordinando outras modalidades de saberes. A verdade não é total nem definitiva nem universal, como nos fazem crer, mas histórica, isto é, produzida sob determinadas relaçóes sociais de antagonismo, ou seja, de classe; ela é, portanto, temporalizada e o discurso que organiza a sua compreensão e difusão demarca um limite provisoriamente estabelecido por relações de força e pelo confronto de interesses.

\section{Exclusão e inclusão: nitidez ou nebulosidade?}

Qualquer pessoa, mesmo com escassa escolaridade, entende o que significa exclusão, e o seu contrário, a inclusão. Tratando-se da exclusão social, poderíamos buscar na História uma infinidade de exemplos que mostram as margens exatas do conceito aplicado à realidade. Como exemplos, poderíamos indicar as mulheres impedidas de parti- 
Exclusāo e educação social: conceitos em superfície e fundo

cipar das Olimpíadas, na Grécia antiga; as mulheres hebréias excluídas do convívio quando eram declaradas "impuras"; no Brasil, negros excluídos de clubes recreativos de brancos; indígenas excluídos de suas terras e condiçôes de sobrevivência; agricultores excluídos das possibilidades de continuar a reproduzirem-se como tais por falta de uma política agrícola voltada aos seus interesses.

Ferraro (1999) constrói o conceito de exclusão da escola e de exclusão na escola para identificar fenômenos de não-acesso, evasão, reprovação e repetência de crianças das camadas populares; ${ }^{4}$ já Foucault (1996), em sua Aula Inaugural no Collége de France, pronunciada em 2/12/1970, aborda as formas de interdição ou de exclusão do discurso, mostrando que essa exclusão se concretiza materialmente, de diferentes formas e com diferentes justificativas.

Até aqui o conceito tem uma propriedade fantástica; ele não deixa dúvidas a respeito da mensagem que transmite. Ele é transparente. Mas é nessa transparência que reside a sua fragilidade, porque, se ele corresponde exatamente à realidade empírica cuja superfície mostra, no entanto ele não consegue ir além desta, ou seja, não explica as razões que colocam algumas pessoas do lado de fora e outras do lado de dentro; não identifica o(s) espaço(s) e o(s) tempo(s) nos quais acontece, não nomeia os sujeitos que decidem quem será incluído ou excluído, muito menos as suas justificativas. $\mathrm{O}$ que amarra o conceito ao empírico para explicitarse é o mesmo que encerra a sua compreensão dentro deste limite. É um conceito meramente descritivo e, como tal, tem alguma utilidade, entretanto apresenta-se como impessoal e neutro. Sem um adjetivo que o qualifique (social, escolar...), é abstrato, e para concretizar-se relaciona, de maneira contraditória, seres humanos posicionados como sujeitos que excluem, de um lado, ou como objetos que são excluídos, de outro. Eis alguns riscos de seu uso quando não se tem à mão o concurso de categorias analíticas que possam ampliar a compreensão do que exclusão e inclusão tão propriamente descrevem, ou, por outra, sem recorrer aos processos históricos em cuja lógica está incluída a exclusão, como faz Marx (1982).

Não vou estender-me sobre a análise do conceito "exclusão" porque isso já foi feito em Ribeiro (1999a), mas apenas retomá-lo nas condições históricas que lhe conferem visibilidade, na tentativa de criar um vínculo deste conceito com o de educação social, para demonstrar minha hipótese de trabalho. 
No que é chamado de exclusão se destacam dois pontos: os enfrentamentos com situações de dominação que explicam o surgimento de "novos movimentos sociais" (Ribeiro, 1998) e a emergência de uma nova questão social caracterizada pelo desemprego, pelo surgimento de uma "nova pobreza" e, em decorrência, pela violência que marca os processos migratórios na Europa (Castel, 1998; Forrester, 1997). O conceito "exclusão" tem o mérito de ampliar a compreensão de problemas que fazem parte das relações sociais no modo de produção capitalista, mas que não podem ser explicados tão-somente pela expropriação da terra ou pela apropriação do produto do trabalho, dos meios de produção e de sobrevivência. A nova questão social que dá evidência aos excluídos dos benefícios da riqueza produzida socialmente também inclui, no debate, a opressão, a discriminação e a dominação, exigindo um tratamento teórico-prático adequado, tendo por base as relações sociais de exploração/ expropriação, próprias do modo de produção capitalista.

Todavia, mesmo tendo este mérito - o de revelar questóes que ficam, muitas vezes, subsumidas na análise das relações de conflito entre as classes sociais -, o conceito de exclusão é limitado, e a sua utilização indiscriminada "reveste-se de imprecisão e carece de rigor conceitual" (Oliveira, 2004). Além de sua imprecisão, ele é impotente para a formulação de estratégias de ruptura com aquelas relações, as quais determinam que uma minoria decida sobre a exclusão social da terra, do trabalho e das condições de subsistência da maioria dos povos.

O contrário da exclusão é a inclusão, o estar dentro, o re-ingresso à condição da qual foi excluído(a). Da mesma forma, há sujeitos sociais com o poder de incluir e há os que são considerados objetos e, portanto, que são incluídos ou que, numa perspectiva assistencialista e de manutenção do status quo, são colocados para "dentro" novamente. Se considerarmos que os processos de exclusão social são inerentes à lógica do modo de produção capitalista, veremos que as políticas de inclusão e/ou inserção social são estratégias para integrar os objetos - os excluídos - ao sistema social que os exclui e, ao mesmo tempo, de manter sob controle as tensões sociais que decorrem do desemprego e da exploração do trabalho, móveis da exclusão social.

Esse, portanto, é o limite do conceito "exclusão". Ele oculta a postura autoritária da classe que opta por acomodar os conflitos, armarse contra a violência, porque não pretende atravessar a superfície do fenômeno para ir ao fundo, ou à sua essência. Nesse fundo é possível ver 
Exclusāo e educação social: conceitos em superfície e fundo

a barbárie que avança tanto sobre as populações pobres quanto sobre as condições de sobrevivência no planeta Terra, tendo em vista a necessidade de preservação dos recursos naturais não-renováveis e que são essenciais à manutenção da vida.

Educação social: engodo ou alternativa?

\section{Contextualizando a questão}

Meu ingresso no debate sobre "educação social" é, por um lado, recente, e explica-se em razão de interesses de pesquisa manifestos por orientandos de pós-graduação; por outro, é bem antigo e está vinculado a uma práxis com movimentos sociais populares, com educação popular e a pesquisas daí decorrentes, desde o final dos anos de 1970. Desafiou-me, sobretudo, o conceito de educação social porque o segundo termo da expressão, o "social", parece-me, num primeiro momento, configurar-se como uma redundância, ou figura de linguagem chamada pleonasmo. ${ }^{5}$

Pesquisas feitas até o momento permitem intuir que um feroz combate se trava entre projetos sociais e educacionais, ocultos sob esta expressão - "educação social". Mergulhar um pouco na gênese e trajetória do conceito é necessário para explicitar sua contradição, ao anexar uma qualidade ou atributo - social - que é inerente à substância ou conceito "educação". Se o social, como o mundo de relações em que se efetuam os processos de sociabilidade, é o substrato no qual se realiza a educação, como entender que esta ocupe o lugar do substantivo ou daquele que é adjetivado na expressão "educação social"?

O conceito de educação social está indissociavelmente vinculado ao de exclusão, como veremos. É como uma resposta afirmativa e adequada que a educação social emerge no debate sobre: Que educação oferecer aos milhares de crianças, adolescentes e adultos excluídos da e na escola; do e no emprego; da e na terra; das e nas instituições sociais? Seriam os educadores formados por instituições regulares de ensino, dentro dos princípios, objetivos, conteúdos e métodos tradicionalmente direcionados aos incluídos, os mais preparados para educar os que experimentam as situações de exclusão social?

$\mathrm{O}$ universo que esta questão comporta e os limites deste artigo me obrigam a fazer um recorte para, apenas e sucintamente, desenvol- 
ver uma análise a partir de experiências e discussões feitas no Uruguai e no Brasil sobre educação social. Esta análise pretende contribuir para se pensar a formação de professores, feita nas licenciaturas e nos cursos normais superiores.

\section{A educação social em outros países - algumas notícias}

Um pouco da História remete-nos aos processos de reconstrução da Europa, no pós-guerra, quando uma educação diferente se afirmou como necessidade para integrar socialmente jovens órfāos de guerra. É a partir dessa necessidade que $o$

Alto Comisionado de la República de Francia en Alemania organizó (...) en 1949, un Encuentro Internacional sobre "Los problemas de la educación de los jóvenes inadaptados". La finalidad era favorecer, tras la guerra, una mejor comprensión entre alemanes y franceses que se ocupaban de estos problemas. (AIEJI, 2005)

É nesse contexto que foi criada a Associação Internacional de Educadores Sociais (AIEJI), para educar jovens órfāos "inadaptados". Na Europa, portanto, a proposta de uma educação social configurou-se como diferente da que era oferecida pela escola regular, tendo como público-alvo crianças e adolescentes. Estes haviam perdido suas famílias na Segunda Guerra Mundial e precisavam de uma assistência educativa para poder se readaptar à nova situação de "sem-famílias". De um certo modo, corresponderia a uma educação especial, embora não se destinando, especificamente, como esta, a portadores de necessidades especiais. ${ }^{6}$ Esta preocupação inicial com órfãos de guerra tomou outro rumo. Nos anos de 1990, em países como França e Espanha, a educação social passou a focalizar crianças e jovens em situação de vulnerabilidade social, tendo em vista a massificação do desemprego e seus resultados no que concerne à desagregação familiar e à violência social (INAME, 2003).

Uma Rede de Educadores Sociais para a América Latina (REDSAL) está em vias de construção. Reúne educadores de Uruguai, Chile, Venezuela e Argentina. Nos marcos de uma larga tradição e de uma história de luta pela paz, solidariedade e participação dos povos inscreve-se a educação social na América Latina (Camors, 2004). Ao explicitar o significado da educação social no Chile, Martinez (2004) procura associá-la a uma perspectiva de desenvolvimento humano sustentável, 
Exclusāo e educação social: conceitos em superfície e fundo

aludindo às potencialidades que esta modalidade de educação pode oferecer de inserção e de participação "en la nueva sociedad global del conocimiento".

A oportunidade de ter acesso a documentos, relatos e publicações sobre a experiência do INAME justifica a análise da educação social que vem sendo desenvolvida no Uruguai para contrapor a análise de experiências que se realizam no Brasil.

\section{Educação social no Uruguai}

No Uruguai, a educação social começa a estruturar-se em 1985 dentro do processo de redemocratização do país, que se encontrava, como o Brasil, num regime de ditadura. Surge em contraposição à especialização, que a caracteriza na França e na Espanha, e resulta da organização de um coletivo de educadores preocupados com a situação de crianças e jovens vivendo nas ruas e para os quais a escola já não fazia nenhum sentido. Esses educadores não negam a função específica da escola, que julgam ser o ensino, mas pensam a educação social para além dos conteúdos transmitidos pela escola e como um espaço educativo qualificado de vida para crianças e adolescentes colocados socialmente em situação de risco. Desse modo justificam o acréscimo de "social" à educação.

Essa modalidade de educação exige um educador com uma formação em nível superior, porém mais ampla e diferenciada da que é oferecida aos professores que irão trabalhar com ensino regular. Não se trata de preparar um professor para aplicar um currículo dentro de uma instituição social nem de perceber os jovens como quem deve adaptar-se a esse currículo e à educação escolar. O educador social subverte esta lógica. Não se trata, também, de uma educação vazia de conteúdos, porém estes não são os transmitidos pela escola e sim os deliberados coletivamente pelos educadores sociais, a partir de questões e necessidades dos educandos na qualidade de sujeitos sociais. A fronteira entre um professor e um educador social é uma questão de território. Uma educação social, nessa perspectiva, funda-se em princípios que vêem a totalidade da pessoa humana, porquanto abrange as diferentes experiências de vida dos educandos, exigindo, em decorrência, conteúdos, métodos e instrumentos concernentes com aqueles princípios. Educadores sociais, no Uruguai, trabalham em equipe com outros profissionais: psicólogos, médicos, assistentes sociais, professores... ${ }^{7}$ 
Nos depoimentos colhidos durante o III Fórum Mundial de Educação (FME) e nos textos - Una educación social para el Uruguay (INAME, 2003) e La educación social: un marco referencial (INAME, s/d.) - podemos perceber, naquela perspectiva de atravessar a superfície para adentrar ao fundo, que a educação social, no país referido, constrói-se num processo de luta e enfrentamento de concepções e práticas pedagógicas formais e não-formais. A organização do coletivo de educadores sociais, existente há mais de 15 anos, tem sido bastante forte para obter o reconhecimento do Estado quanto à necessidade de qualificar a educação das crianças e dos adolescentes de rua, por meio da oferta de formação aos educadores sociais e da admissão de um currículo construído coletivamente, que incorpore demandas das populações-alvo por políticas educativas, consideradas sujeitos de direitos e deveres. Para isso

Se ha creado la nueva figura del Educador Social a partir de la formación de nivel terciario no universitario, que recoge la experiencia de los educadores para mejorar la acción profesional que los niños requieren y a la cual tienen derecho. (INAME, 2003, p. 3.)

Uma análise dessa experiência, ainda que limitada pela exigüidade de informaçôes, ressalta sua potencialidade como um campo de experimentação de estratégias de formação de novos sujeitos sociais de direitos. Orienta-se, portanto, por uma visão que aponta para a constituição de uma cidadania ativa no sentido que lhe é dado por Canivez (1998). Entretanto, pergunta-se: Quais os seus limites? Mesmo com a oferta de uma educação que pretenda ser integral, de que modo essas crianças e esses jovens, ao tornarem-se adultos, serão integrados à sociedade que os reproduz como "excluídos" institucional e socialmente?

Direcionando ainda mais a pergunta: Haverá trabalho - empregos assalariados protegidos por lei - para esses jovens, com condições dignas de re-construírem suas vidas? Poderão exercer uma cidadania ativa no que concerne aos direitos fundamentais de trabalho, saúde, educação, moradia e segurança, sendo o Uruguai um país capitalista periférico, como o Brasil? Não estaria, enfim, a educação social pública, oferecida por intermédio do INAME, refletindo uma estratégia de controle de conflitos sociais por parte dessas crianças e desses jovens que não podem ficar entregues a si mesmos?

Em contrapartida, deixar no abandono crianças e adolescentes colocados em situação de vulnerabilidade traria alguma forma de contri- 
Exclusāo e educação social: conceitos em superfície e fundo

buição a uma transformação social, ou seria uma maneira descomprometida socialmente, e, portanto, irresponsável, de fechar os olhos à continuidade da barbárie que decorre dos processos sociometabólicos destrutivos do capital? (Mészáros, 2002). A cidadania, pensada originalmente para o indivíduo burguês pelos teóricos do liberalismo social, poderia concretizar-se na realidade dos países pobres, endividados com o Fundo Monetário Internacional (FMI), e sob a ótica do liberalismo econômico em sua forma reacionária, identificada como neoliberalismo?

Assim, a pergunta central que emerge do fundo é: Qual o potencial de transformação e de controle de conflitos contido nas políticas públicas dirigidas a populações colocadas em situação de vulnerabilidade social, pelo modo de produção capitalista, em que, pela sua própria natureza, não há lugar para todos? Ou, por outra, como deixar visíveis as contradições do que se pretende como educação social, que é efetuada dentro desse modo de produção, no que tange às possibilidades de rupturas, de um lado, e às amarras estruturais que as limitam, de outro? Sem isso, pode-se cair numa visão idealizada da sociedade e da vulnerabilidade da infância e da adolescência, como se a educação social, por si, fosse capaz de superar essa vulnerabilidade. No entanto, sem a educação social, por um outro prisma, pode-se cair em outro extremo, o do imobilismo irresponsável, sem visão histórico-dialética, que crê ser necessário esperar pela revolução social para, só depois, ver o que se faz com as crianças e os adolescentes excluídos das condições sociais e educacionais mínimas de humanização.

\section{Recortes de experiências de educação social no Brasil}

Essas questões, de certa forma, vão ser retomadas nas experiências brasileiras de educação social, nas quais o confronto de interesses não se destaca pela crítica às instituiçôes de ensino formal (escolas e universidades), como no Uruguai, embora ela apareça também. O confronto está mais diluído, uma vez que a educação social pode, como no Uruguai, ser uma política pública, e, diferente do Uruguai, ser uma iniciativa de escolas, universidades e organizações não-governamentais (ONGs). Tanto como política pública quanto como iniciativa de instituições e/ ou organizações sociais, a educação social está voltada, pelo menos em princípio, para a formação do(a) cidadão(ã). Apresenta uma visão crítica, mas sem aprofundá-la, da sociedade que produz as condições mate- 
riais e sociais de vulnerabilidade e/ou de exclusão social de adultos, jovens e crianças.

Pretendo deter-me em trabalhos de extensão e formação desenvolvidos pela Universidade Federal do Rio Grande do Sul (UfRGS) (Faculdade de Educação e Escola Superior de Educação Física); trabalhos de ensino-pesquisa-extensão desenvolvidos pela Universidade Federal de Pelotas (UFPEL); trabalhos de educação popular, na perspectiva da formação, desenvolvidos pela organização não-governamental (ONG) Instituto de Humanização (IDH), Universidade Popular Paulo Freire (UPPF); políticas desenvolvidas pela Prefeitura Municipal de Porto Alegre/RS; estudos registrados pela revista Sonho Possivel - Revista de Educação Popular, do Centro Universitário La Salle; e pesquisas desenvolvidas por Maria Stela Graciani, sistematizadas em Pedagogia social de rua (2001). Convergem esses trabalhos, políticas, estudos e pesquisas em um ponto: o terem a Lei Orgânica da Assistência Social (LOAS), n. 8.742/1993, e o Estatuto da Criança e do Adolescente (ECA), n. 8.069/1990, como referência.

Vou pinçar alguns elementos desses trabalhos, experiências e estudos antes enumerados, com a finalidade de trazer à luz um pouco do fundo que se oculta sob a superfície das concepções, das práticas de educação social, e das políticas que a concretizam. Corro o risco da fragmentação e da parcialidade, considerando que os limites do texto me impedem de aprofundar a análise, mas arrisco-me no sentido de cumprir com o objetivo proposto, tendo em vista a necessidade de demonstrar a hipótese de trabalho.

Começo pelos trabalhos de formação, ensino-pesquisa-extensão, desenvolvidos pelas universidades. $\mathrm{O}$ curso de extensão para educadores sociais, promovido pelo Núcleo de Pesquisa e Extensão em Educação, Exclusão e Violência Social, da FACED/UFrgS, desenvolveu uma discussão, coordenada pela Profa-Dra Carmen Maria Craidy (15/8/2002), sobre "O papel do educador social: desafios e perspectivas". No programa desse curso (p. 2) está a afirmação de que as características da nossa sociedade fazem com que:

os chamados "excluídos" exijam um investimento humano suplementar para que exerçam seus direitos de membros da sociedade e tenham a possibilidade de um adequado desenvolvimento pessoal. Esse investimento suplementar é que criou a figura do educador social que veio substituir as 
Exclusāo e educação social: conceitos em superfície e fundo

figuras repressivas e/ou assistenciais que o precederam. ${ }^{8} \mathrm{~A}$ figura do educador social é, assim, inseparável do avanço da consciência de direito.

No mesmo texto, o educador social é definido como um militante ou um funcionário que busca uma forma de trabalho assalariado, mesmo que destituída da proteção de leis trabalhistas, dificultando o estabelecimento de fronteiras entre os diferentes educadores sociais, cujo trabalho também pode ser caracterizado como de educação popular e/ou não-formal. Na visão do referido curso, o trabalho do educador social está voltado para aqueles "que não estão inseridos nas instituições educacionais mais regulares, tais como a família e a escola”.

Nessa mesma linha de pensamento e dentro de seu programa de extensão universitária, a ESEF/UFRGS, junto com o Centro Universitário fEevale e a Fundação de Atendimento Sócio-Educativo (FASE), de Porto Alegre, realizou um ciclo de palestras para educadores sociais, com o título (Re)pensando a intervenção educativa, em dezembro de 2003. Tinha por objetivo "propiciar uma reflexão multidisciplinar e integrada com agentes sociais sobre o trabalho de educação social, especialmente dirigido à realidade da periferia urbana” (Programa, f. 1).

O Programa de Extensão Círculos Culturais de Lazer, Saúde e Educação, da ESEF/UfPel (2004), de Pelotas/RS, com apoio do Ministério da Educação (MEC), tem um projeto de pesquisa associando extensão e ensino - Práticas de extensão universitária e formação de educadores sociais. O objetivo do Programa é oferecer aos educadores sociais uma formação direcionada à intervenção no campo da educação não-formal, "comprometida com o atendimento de populações e grupos excluídos socialmente" (p. 4). Situando o contexto em que será desenvolvida a pesquisa-intervenção de capacitação de educadores sociais pela ESEF/ UFPEL, há o propósito de:

proporcionar aos grupos espaços de experimentação de um pensamento capaz de dobrar-se radicalmente diante dos saberes do corpo, de constituirse em contraponto à linguagem escolar formalizada e conceitual, o complexo e diverso campo dos saberes escolares atravessado por linguagens marginais constitutivas de um rico universo simbólico, que encontra suas referências na cultura em seu caráter local, particular, temporal, global, revolucionário. (Pardo, 2004, p. 3)

O Programa Familia, Apoio e Proteção da Fundação de Educação Social e Comunitária (FESC), da Prefeitura de Porto Alegre, apresenta 
três objetivos gerais, dos quais destaco o primeiro: "Buscar a modificação das situações de vulnerabilidade a que estão expostas as crianças e os adolescentes no seio de sua família, estimulando a convivência familiar e comunitária" (p. 5). ${ }^{9}$

Há outros estudos que focalizam a educação social sob a ótica da educação popular e os educadores populares como "educadores de rua". O Centro Universitário La Salle, em Porto Alegre/RS, desenvolve trabalhos de educação popular com jovens e adultos, mas também com meninos e meninas de rua. Publica estudos sobre o tema, alguns deles produzidos por seus próprios educadores populares, na revista Sonho Possivel - Revista de Educação Popular. O trabalho de educação popular desenvolvido pelo La Salle decorre da experiência do Programa Ensinando e Aprendendo com Jovens e Adultos (EAJA), iniciado em 1995 e coordenado pelo curso de pedagogia desse Centro, o que mostra o envolvimento de uma licenciatura com o trabalho de educação de jovens e adultos. A revista resulta de um

trabalho conjunto de reflexão sobre as práticas exercidas nos últimos dois anos de implantação da educação de jovens e adultos no Centro Universitário La Salle, bem como as contribuições de profissionais que não atuaram diretamente no programa, mas estão envolvidos de uma ou de outra forma com educação de adultos ou outras experiências em educação popular. (Fontebasso, Editorial, 2001, p. 7)

Ampliando a discussão, Graciani (2001) efetua uma análise do que identifica como pedagogia social de rua, sobre a qual, em seu Prefácio, afirma Gadotti (apud Graciani, 2001, p. 13): "A pedagogia do educador social é, de certa forma, uma contrapedagogia que busca instaurar uma nova cultura, a cultura da solidariedade que possa neutralizar a banalização da vida à qual as elites brasileiras se acostumaram". A autora nomeia educador social de rua, acrescentando um novo termo "rua" - que espacializa a tarefa do educador e o identifica como aquele que desenvolve a sua ação pedagógica entre crianças e adolescentes "em situação de risco pessoal e social, que têm dificuldades de inserção social (...)", conforme determina a LOAS e o ECA, citados anteriormente (Graciani, 2001, p. 26).

A pedagogia social de rua, proposta por Graciani, exige uma competência técnica para trabalhar com uma realidade que não corresponde ao espaço, ao tempo, aos conteúdos e métodos da escola 
formal, articulada a um compromisso político com os educandos. Para isso, as práticas pedagógicas do educador social de rua precisam estar orientadas de modo que propiciem o resgate da cidadania dos sujeitos sociais com os quais desenvolve seu trabalho. Sua concepção de educador social de rua sustenta-se sobre a educação popular, principalmente no pensamento pedagógico de Paulo Freire, para quem teoria e prática são momentos indissociáveis de um mesmo processo (op. cit., p. 309).

As experiências e reflexões sobre educação social no Brasil analisadas até aqui têm algumas identificaçóes com as que se fazem no Uruguai, em termos de políticas sociais; dos educandos - crianças, jovens e adultos em situação de vulnerabilidade; da afirmação de que o trabalho com estas populações exige uma nova pedagogia, um novo currículo, conteúdos e métodos adequados às necessidades dos educandos; da visão de integralidade da educação, nos seus aspectos teórico-práticos, envolvendo o conhecimento, o corpo e a sensibilidade; da finalidade, que tem no resgate da cidadania dos sujeitos o ponto central do trabalho pedagógico. Há, sobretudo, consciência de que existe uma relação entre a exclusão social e educacional e um sistema social produtor dessa exclusão, porém não chega a aprofundar-se a análise de que a pobreza e as condições de vulnerabilidade de adultos, crianças e jovens são produzidas dentro de um contexto determinado por relaçóes sociais de exploração do trabalho e de expropriação da terra e dos meios de produção e sobrevivência.

Tratando-se das diferenças, a mais evidente parece-me ser o fato de, no Uruguai, existir uma instituição pública responsável pela formação tanto dos educadores sociais quanto dos educandos - crianças e adolescentes colocados em situação de risco. Nesse país, os educadores sociais precisam ter completado o ensino médio para ingressar numa formação não-acadêmica, específica para educadores sociais, porém em nível superior, feita pelo Centro de Formación y Estudios del INAME.

No Brasil, há iniciativas de educação social, partindo de instituições públicas (universidades), de poderes públicos (prefeituras), de instituições privadas (universidades), de organizações da Sociedade Civil, como ONGs. ${ }^{10}$ Também se pode observar que, atravessando as experiências e conceitualizações de educação social/popular, há projetos sociais e educacionais em disputa, que nem sempre se tornam claros. Em documentos, análises e relatos de algumas experiências é possível perceber um ocultamento de concepções, métodos e práticas de educação popular 
historicamente construídos pelos movimentos sociais, como se a educação social pensada em espaços formais, diferenciados dos que são produzidos por aqueles movimentos, pudesse avançar para a conquista da cidadania. Observa-se mesmo uma contradição que se manifesta na crítica à escola como instituição formal, e, ao mesmo tempo, nas propostas e políticas de educação social que surgem com alguma forma de vínculo com o Estado ou por dentro de instituições e/ou organizações sociais.

Nas reflexões feitas por Graciani, a expressão "pedagogia social" parece incorporar a relação entre trabalho e educação, que caracteriza a pedagogia socialista e que pode ser observada no que é proposto para as práticas de educação popular: "As formas de organização do trabalho em cada atividade educativa; o próprio processo de conhecimento que se realiza nessas atividades" (Graciani, 2001, p. 39).

\section{Algumas considerações dilaceradas entre superfície e fundo}

Alguns elementos podem ser destacados quando se faz a relação entre os dois conceitos aparentemente separados e autônomos - exclusão e educação social. Poder-se-ia resumir essa relação afirmando que a educação social é uma necessidade que decorre da exclusão social de crianças e jovens ${ }^{11}$ das condições mínimas de sobrevivência, e, inversamente, que a educação social é potencializadora de alternativas a tais crianças e jovens excluídos socialmente.

Julgo que o questionamento ao conceito de exclusão e às políticas de inclusão já foi feito, de modo que vou problematizar a educação social.

A Propuesta del Centro de Estúdios del InAme (2003), explicitada em seus textos e nos depoimentos de seus educadores, faz-nos retomar o fundamento da escola moderna. A fragmentação dos processos de trabalho e a apropriação de seu produto por alguém alheio ao produtor, no modo de produção capitalista, produzem a alienação desse produtor de seu produto e de si mesmo como gênero humano (Marx, 1989). Daí decorre a sua formação, que deixa de ser feita no trabalho e passa a efetuar-se na escola e para o trabalho (Enguita, 1989; Pistrak, 2000).

Os educadores uruguaios afirmam que a escola se identifica com o ensino e que a educação social vai além do ensino, para abarcar o conjunto das atividades que os educandos desenvolvem no cotidiano, considerando-se os aspectos físicos, psíquicos e intelectuais. Tem-se aí uma re- 
Exclusāo e educação social: conceitos em superfície e fundo

tomada da perspectiva grega de educação integral para o cidadão. Esta formação referida à cultura grega já mereceria cuidados pelo fato de a cidadania grega excluir as mulheres, os escravos, os trabalhadores, os camponeses e as crianças (Ribeiro, 2002). A esse cuidado seria necessário anexar outra preocupação. Quando não se chega à raiz da especialização do ensino, que é o trabalho fragmentado, decidido e apropriado de fora, por parte de um sujeito que não produziu, tem-se uma visão idealizada da sociedade e da educação, em que foi suprimida a realidade produtora da exclusão social das condições materiais e espirituais, dignas de existência, que está na origem da vulnerabilidade das populações-alvo da educação social. Por último, restaria perguntar se uma educação que privilegie as atividades do cotidiano dentro do sistema capitalista, que exclui do trabalho e da escola, não seria uma educação para o conformismo a esse sistema social produtor da exclusão.

A questão mereceria um debate bem mais aprofundado sobre o confronto entre a Escola Nova (ou a educação ativa), que substitui trabalho por atividade e cuja finalidade é a educação para o trabalho, e a pedagogia socialista, articulada aos processos revolucionários, cujo propósito é a articulação entre o trabalho produtivo e o ensino (Nosella, 1986; Pistrak, 2000; Makarenko, s/d.). Esta discussão hoje assume novos contornos, tendo em vista o desemprego, a desestruturação do Estado do Bem-Estar Social e a força das políticas neoliberais. Mas seria muito longo abordá-la. Basta lembrar que aquelas propostas de escola ativa e de trabalho e educação foram forjadas em contextos nos quais os processos de industrialização capitalista necessitavam de uma força de trabalho pelo menos escolarizada; os movimentos operários estavam fortemente organizados e tinham projetos para uma sociedade e educação socialistas. Há hoje uma realidade diferente que produz/reproduz uma força de trabalho como mercadoria supérflua, e, em vista disso, uma situação adversa aos movimentos operários, incluindo a perda de direitos sociais conquistados historicamente pela classe trabalhadora.

Nas experiências brasileiras não se pode observar uma uniformidade. De um lado, aparece a educação social como uma política de inclusão, ou como formação de educadores voluntários, ou como ensino, pesquisa, extensão em cursos de licenciatura. Há um propósito de formar educadores sociais para atuarem com crianças, jovens e adultos das camadas populares que estão vulneráveis em conseqüência da pobreza, do desemprego e da violência. Nesse caso, o conceito de educação social 
oculta o de educação popular, encharcado de história, ou seja, de luta das camadas populares por educação pública de qualidade. De outro, os estudos de Graciani (2001), bem como a proposta de Pedagogia da Terra, do Movimento dos Trabalhadores Sem Terra - MST (ITERRA, 2002), parecem resgatar o debate e as experiências de relação entre trabalho e educação, sistematizadas no pensamento socialista (Ribeiro, 1999b).

No primeiro caso, a ocultação da educação popular ou a despolitização do conceito de educação social mostra a força das políticas neoliberais que precisam, contraditoriamente, apertar e afrouxar os laços da vulnerabilidade, que garantem às classes proprietárias dos meios de produção e subsistência a submissão e os baixíssimos custos do valor da força de trabalho, mesmo quando esta é qualificada. Isso porque a educação popular, principalmente após o final dos anos de 1970, no Brasil, é uma iniciativa dos movimentos sociais populares na qualidade de sujeitos coletivos, e a educação social é uma iniciativa ou de instituições sociais ou do Estado, embora assentada sobre uma legislação que teve um certo grau de participação social (ECA). No segundo caso, Graciani (2001) resgata experiências, conteúdos e métodos de uma pedagogia social do povo de rua, que, nas suas lutas, confere-lhe novos contornos, os quais vão re-desenhando a sociedade e a educação que as classes populares demandam.

Diferindo dessas experiências, o MST toma a frente de outros movimentos de luta pela terra, reunidos internacionalmente na Via Campesina, e compartilha com eles da feitura de uma formação herdeira das experiências e das reflexões socialistas. Inspirada na pedagogia social presente nas experiências de Pistrak e Makarenko na Rússia pósrevolução, a formação que vem sendo feita pelo ITERRA, tanto em nível médio como superior, tem como princípios: a realidade, o trabalho e a auto-organização dos educandos. Ao passo que as experiências de educação social são predominantemente urbanas, propostas pelo Estado e por organizações e/ou instituiçôes sociais, as do ITERRA são limitadas aos movimentos sociais populares campesinos e distanciam-se da educação social ao colocar-se na perspectiva de uma pedagogia social. Vinculadas aos movimentos de luta pela terra de trabalho, a educação proposta pelo MST orienta-se por projetos de sociedade e de educação socialista.

Retomando a História por intermédio de autores como Durkheim (1998), que reflete sobre o papel das universidades na educação social, de Froumov (s/d.), que busca registrar a luta da Comuna de Paris pela 
Exclusāo e educação social: conceitos em superfície e fundo

democratização da escola e da instrução pública, de Pistrak (2000) e Makarenko (s/d.), que, nas suas obras, fazem referência a uma pedagogia social, é possível captar que uma pedagogia socialista vem sendo construída numa relação de antagonismo e confronto com a pedagogia liberal.

No caso de Durkheim e Froumov, temos como referência a Guerra Franco-Prussiana (1870-1871), durante a qual se organiza a Comuna de Paris para defender esta cidade da invasão da Prússia. "Les communards voulaient l'égalité de l'instruction. Ils voulaient faire de l'école primaire 'plébeiènne' et misérable une école donnant une instruction élémentaire complète à tous les enfants d'un âge déterminé" (Froumov, s/d., p. 47).

Durkheim aponta o dia seguinte após a guerra de 1870 como o do início da reorganização do ensino superior por parte de "los hombres de iniciativa" (op. cit., p. 189). Ao referir-se às universidades populares, afirma:

Esta es la causa del gran interés en multiplicar los puntos de contacto con la masa de la nación, sobre todo con los sectores de la población donde algo nuevo está en proceso, donde, como consecuencia, se fermenta una vida tumultuosa que demanda orientación. (...) Que las universidades populares sean útiles, es lo que un espíritu liberal no puede negar. (Durkheim, 1998, p. 202)

Pistrak e Makarenko, em condiçōes muito difíceis para um país pobre e em processo de consolidação de uma revolução social, formulam alguns elementos básicos da pedagogia socialista, nos quais se inspira o MST em sua proposta de educação.

Nesse processo histórico de confronto entre projetos de sociedade e de educação podem estar compreendidas as experiências e reflexões que se fazem hoje sobre a educação social na América Latina.

A questão sobre uma (im)possível educação social é muito mais complexa do que aparentemente se mostra. Ela oculta a contradição que sustenta a sua unidade dialética precária porque contraditória, cuja fragilidade/força se deve à disputa de projetos sociais (...); essa disputa por hegemonia na sociedade e na educação pode ser visualizada pelo acréscimo do "social" a esta última, carregado de sentidos. (Ribeiro, 2005, p. 211-212)

Nestas considerações dilaceradas entre superfície e fundo, registro a minha angústia diante dos enormes desafios que se impõem aos trabalhadores, em particular aos da educação, aos operários e campo- 
neses, para confrontar-se com os interesses do capitalismo, em sua atual versão neoliberal globalizada. Penso que seja necessário ter-se mais clareza acerca dos conceitos, na qualidade de ferramentas de luta, com os quais trabalhamos e elaboramos propostas. Do contrário, corremos o risco de estar reformando o "velho" com a ilusão de estar forjando o "novo", porque, aos trabalhadores cabe:

se apossar primeiro de certas palavras-chave (que não podem ser compartilhadas com outras classes, que não estão empenhadas ou que não podem realizar aquelas tarefas sem se destruírem ou sem se prejudicarem irremediavelmente). Em seguida, deve calibrá-las cuidadosamente, porque o sentido daquelas palavras terá de confundir-se, inexoravelmente, com o sentido das ações coletivas... (Fernandes, 2003, p. 57)

Por essas razões, a substantivação da educação articulada à adjetivação do social, produzindo-se um pleonasmo como figura de linguagem, ou, então, o atributo tomado pela substância, ainda suscita muitas dúvidas.

Recebido em agosto de 2005 e aprovado em novembro de 2005.

\section{Notas}

1. Pós-modernidade não é um conceito unívoco. Para Santos (1994), é provisório e nomeia um período de transição tendo em vista que questōes postas pela modernidade não foram nem poderão ser resolvidas, mas ainda não se sabe o que virá a substituí-la. Tomo o discurso da pós-modernidade como ideologia (Torres, 1996), porquanto as teorias que a sustentam não foram produzidas no âmbito das ciências sociais e sim desde a crítica literária. Portanto, não se propōem questōes de caráter global, sendo, isso sim, um pensamento fragmentado que despolitiza o debate sobre a sociedade e a educação. No mesmo sentido, tomo a globalização como ideologia enquanto abstrai as condiçōes objetivas e subjetivas das populações atingidas pelos processos de reprodução do capital, nos diferentes aspectos da vida humana, como resposta à mais intensa e duradoura crise de acumulação (Coraggio, 1999).

2. "A acumulação flexível é marcada por um confronto direto com a rigidez do fordismo. Ela se apóia na flexibilidade dos processos de trabalho, dos mercados de trabalho, dos produtos e padrōes de consumo" (Harvey, 1998, p. 140).

3. Shapiro reconhece, em Baudrillard, o filósofo francês que aponta para a existência de uma "hiper-realidade". Explicitando o pensamento deste autor, afirma Shapiro (1993, p. 105): "Não há - ou parece não haver - nada a não ser a variedade atordoante de superfícies. Por exemplo, não há nada como olhar através da aparência do 'mercado livre' e enxergar embaixo ou por detrás dela as 'reais relaçốes' que a estruturam".

4. Ferraro (1999, p. 24) utiliza o conceito de exclusão na perspectiva de Marx (1982), ou seja, de processo histórico, sendo este referido à análise da expropriação da terra e da 
Exclusão e educação social: conceitos em superfície e fundo

proletarização do camponês como origem da relação capital x trabalho. Sob esta mesma ótica, Oliveira (2004) faz uma análise da categoria "exclusão" na obra de Marx.

5. "Pleonasmo é o emprego de palavras desnecessárias ao sentido"; Rocha Lima. Gramática Normativa da Lingua Portuguesa. 31. ed. Rio de Janeiro: José Olympio, p. 511, 1992.

6. Crianças e jovens que apresentam alguma deficiência física ou mental e que exigem uma educçẫo diferenciada que atenda às suas necessidades, por isso identificada como educação especial.

7. As informaçōes foram obtidas em dois momentos. O primeiro, em 29/8/2004, na sede do Instituto de Humanização (IDH), em Porto Alegre/RS, estando presentes 14 pessoas, sendo três (3) representantes da AIEJI. As demais eram professores e/ou educadores populares vinculados ao Instituto. O segundo momento ocorreu em 30/8/2004, no Centro de Eventos da Pontifícia Universidade Católica (PUC-RS), durante o III Fórum Mundial de Educação, na mesa-redonda $A$ dívida social em educação pública: diagnóstico, conceitos e experiências, coordenada pelo Prof.-Dr. Alceu Ferraro e da qual fez parte o educador social Jorge Camors, representando a AIEJI - Uruguai, além de mais dois educadores sociais uruguaios.

8. A autora está referindo-se aos profissionais que atuam nas instituiçôes para onde são levados jovens delinqüentes infratores, os assistentes sociais, chamados, estes, por Paulo Freire (1981b) de "trabalhadores sociais" e que poderiam, segundo este autor, desenvolver um trabalho para a mudança social.

9. O documento não apresenta data ou período no qual irá vigorar a política proposta. Os Objetivos (p. 3.1) aparecem como resultados de discussões promovidas em duas reunióes, a de 31 de maio de 1999 e a de 12 de dezembro de 1999. Trabalho com estas datas como referência.

10. Podem ser identificadas, no Brasil, pelo menos duas ONGs que, historicamente, desenvolvem trabalhos de educação social com populaçôes de crianças e jovens em situação de vulnerabilidade: a Fundação São Martinho, no Rio de Janeiro, e a Federação de Órgãos para a Assistência Social e Educacional (FASE), com sede também no Rio de Janeiro, porém com escritórios em outros estados da federação (Souza, 2005).

11. Em algumas iniciativas de caráter público e/ou privado são incluídos adultos como sujeitos de educação social.

\section{Referências bibliográficas} ASOCIACIÓN INTERNACIONAL DE EDUCADORES SOCIALES
(AIEJI). Propuesta marco para el XVI Congreso Mundial de AIEJI, Montevidéu, Uruguai, nov. 2005. Educación social: inclusión y participación. Desafíos éticos, técnicos y políticos. Doc. 22 p. (s/n.)

BRASIL. Lei n. 8.742, de 7 de dezembro de 1993. Lei Orgânica da Assistência Social (LOAS); dispõe sobre a Organização da Assistência Social e dá outras providências. Diário Oficial da Uniāo, Brasília, DF, 8 dez. 1993. 
BRASIL. Lei n. 8.069, de 13 de julho de 1990. Estatuto da Criança e do Adolescente; dispõe sobre o Estatuto da Criança e do Adolescente e dá outras providências. Diário Oficial da Uniāo, Brasília, DF, 16 jul. 1990.

CAMORS, J. Una perspectiva pedagógica para rescatar la función educativa que se realiza en diversos ámbitos de la vida social: la educación social. Trabalho apresentado no 3. Encuentro Nacional de Educadores. Montevidéu, Uruguai, set. 1999. Enviado por mail: censores@adinet.com.uy

CAMORS, J. Los educadores sociales: ¡Son educadores! Editorial. Boletin de la Oficina Latinoamericana de AIEII-LAT, n. 4, p. 1-2, mayo 2004. Disponível em: <http://www.aiejilat.org>.

CANIVEZ, P. Educar o cidadão. 2. ed. São Paulo: Papirus, 1998.

CASTEL, R. As metamorfoses da questão social: uma crônica do salário. Petrópolis: Vozes, 1998.

CORAGGIO, J.L. Las propuestas del Banco Mundial para la educación: ¿sentido oculto o problema de concepción? CORAGGIO, J.L.; TORRES, R.M. La educación según el Banco Mundial. Madrid: Miño y Dávila, 1999. p. 11-74.

CRAIDY, C.M. O papel do educador social: desafios e perspectivas. Porto Alegre: Núcleo de Pesquisa e Extensão em Educação, Exclusão e Violência Social (FACED/UFRGS), ago. 2002. Curso de extensão para educadores sociais. fotocopiado. $4 \mathrm{p}$.

CURY, C.R.J. Educação e contradição. 4. ed. São Paulo: Cortez; Campinas: Autores Associados, 1989.

DURKHEIM, E. Educación y pedagogía. Buenos Aires: Losada, 1998.

ENGUITA, M.F. A face oculta da escola: educação e trabalho no capitalismo. Porto Alegre: Artes Médicas, 1989.

EQUIPO/INAME. La educación social: un marco referencial; para reconceptualizar la función educativa que niños y niñas y adolescentes requieren para ser protagonistas de su tiempo. Montevidéu, 2004. Enviado por censores@adinet.com.uy 
Exclusāo e educação social: conceitos em superfície e fundo

ESEF/UFRGS. Ciclo de palestras para educadores sociais. Projeto Vivências Comunitárias. Programa (Re)pensando a intervenção educativa. Porto Alegre, dez. 2003.

FERNANDES, F. O que é revolução. In: FERNANDES, F. Clássicos sobre a revolução brasileira. São Paulo: Expressão Popular, 2003.

FERRARO, A.R. Diagnóstico da escolarização no Brasil. Revista Brasileira de Educação, São Paulo, n. 12, p. 22-47, set./dez. 1999.

FREIRE, P. Pedagogia do oprimido. 9. ed. Rio de Janeiro: Paz \& Terra, 1981 a.

FREIRE, P. Educação e mudança. 3. ed. Rio de Janeiro: Paz \& Terra, $1981 \mathrm{~b}$.

FONTEBASSO, M.R. Editorial: sonho possível. Revista de Educação Popular, Porto Alegre, v. 2, n. 1, p. 7, abr., 2001.

FORRESTER, V. O horror econômico. São Paulo: UNESP, 1997.

FOUCAULT, M. Verdade e poder. In: Foucault, M. Microfisica do poder. 4. ed. Rio de Janeiro: Graal, 1984. p. 1-14.

FOUCAUlT, M. A ordem do discurso. 2. ed. São Paulo: Loyola, 1996.

FROUMOV. S. La Commune de Paris et la democratization de l'école. Moscou: Du Progrés, s/d.

GRACIANI, M.S.S. Pedagogia social de rua. 4. ed. São Paulo: Cortez; Instituto Paulo Freire, 2001.

HARVEY, D. Condição pós-moderna. 7. ed. São Paulo: Loyola, 1998.

INSTITUTO NACIONAL DO MENOR (INAME). Centro de Formación y Estudios. Hacia la construcción que nos debemos: una educación social para el Uruguay. Montevidéu, 2003.

INSTITUTO TÉCNICO DE CAPACITAÇÃO E PESQUISA DA REFORMA AGRÁRIA (ITERRA). Pedagogia da terra. Cadernos ITERRA, Veranópolis, RS, n. 6, dez. 2002.

KOSIK, K. Dialética do concreto. 2. ed. Rio de Janeiro: Paz \& Terra, 1976. 
MAKARENKO, A. Poema pedagógico en tres partes. Moscou: Progreso, s/d.

MARTINEZ, E.M.N. Educación social en Chile en los albores del siglo XXI. Boletín de la Oficina Latinoamericana de AIEII-LAT, n. 4, p. 4-5, mayo 2004. Disponível em: <http://www.aiejilat.org>.

MARX, K. O capital, livro 1. São Paulo: DIfEL, 1982. v.2

MARX, K. Trabalho alienado e superação positiva da auto-alienação humana. In: MarX, K.; Engels, F. História.. São Paulo: Ática, 1989. p.146-181.

MARX, K. A questão judaica. In: MARX, K. Manuscritos econômico-filosóficos. Lisboa: Ed. 70, 1993. p. 35-73.

NOSELLA, P. Educação tradicional e educação moderna. Educação \& Sociedade, Campinas, n. 23, p. 106-136, abr. 1986.

OLIVEIRA, A.R. Marx e a exclusão. Pelotas: Selva, 2004.

PARDO, E.R. Práticas de extensão universitária e formação de educadores sociais. Pelotas: ESEF/UfPEL, jul. 2004. Projeto de pesquisa. fotocopiado. $17 \mathrm{p}$.

PISTRAK. Fundamentos da escola do trabalho. São Paulo: Expressão Popular, 2000.

PORTO ALEGRE. Prefeitura Municipal. Fundação de Educação Social e Comunitária (FESC). Programa família, apoio e proteção. Porto Alegre, s/ d. Fotocopiado. 16p.

PORTO ALEGRE. Prefeitura Municipal. Fundação de Assistência Social e Cidadania (FASC). Programa municipal de execução de medidas sócio-educativas em meio aberto. Porto Alegre, 2000. fotocopiado. 72p.

PORTO ALEGRE. Prefeitura Municipal. Fórum de Políticas Sociais. Porto Alegre da inclusão social. Porto Alegre: G. Nova Prova, jan. 2002.

RIBEIRO, M. O caráter pedagógico dos movimentos sociais. Serviço Social e Sociedade, São Paulo, n. 58, p. 41-71, 1998.

RIBEIRO, M. Exclusão: problematização do conceito. Educação \& Pesquisa, São Paulo, v. 25, n. 1, p. 35-50, jan./jun. 1999a. 
Exclusão e educação social: conceitos em superfície e fundo

RIBEIRO, M. É possível vincular educação e trabalho em uma sociedade "sem trabalho"? Revista UCPel, Pelotas, v. 8, n. 1, p. 5-28, jan./jun. $1999 \mathrm{~b}$.

RIBEIRO, M. Educação para a cidadania: questão colocada pelos movimentos sociais. Educação e Pesquisa, São Paulo, v. 28, n. 2, p. 113128, jul./dez. 2002.

RIBEIRO, M. Da educação popular à pedagogia da terra: apontamentos a uma pedagogia social. In: Henz, C.; GHIGGI, G. Memórias, diálogos e sonhos do educador. Santa Maria: Pallotti, 2005. p. 201-218.

SANTOS, B.S. Pela mão de Alice: o social e o político na pósmodernidade. 3. ed. Porto: Afrontamento, 1994.

SHAPIRO, S. O fim da esperança radical?: o pós-modernismo e o desafio à pedagogia crítica. In: SILVA, T.T. (Org.). Teoria educacional crítica em tempos pós-modernos. Porto Alegre: Artes Médicas, 1993. p. 103-121.

SOUZA, D.D.L. Organizações não-governamentais: um estudo de caso da Federação de Órgãos para Assistência Social e Educacional - FASE. 2005. 210f. Tese (Doutorado) - Programa de Pós-Graduação em Educação (Ppgedu), Universidade Federal do Rio Grande do Sul, Porto Alegre.

TORRES, C.A. Estado, educación y neoliberalismo en América Latina. In: TORReS, C.A. Las secretas aventuras del orden: Estado y educación. Buenos Aires: Miño y Dávila, 1996. p. 29-52. 